\title{
Socio-economic position and lower dietary moderation among Chinese immigrant women in the USA
}

\author{
Marilyn Tseng ${ }^{1, *}$ and Carolyn Y Fang ${ }^{2}$ \\ 'Department of Kinesiology, California Polytechnic State University, 1 Grand Avenue, San Luis Obispo, \\ CA 93407, USA: ${ }^{2}$ Fox Chase Cancer Center, Philadelphia, PA, USA
}

Submitted 28 October 2010: Accepted 19 June 2011: First published online 2 August 2011

\begin{abstract}
Objective: To examine associations of education and occupation, as indicators of socio-economic position (SEP), with dietary intake and diet quality in a sample of Chinese immigrant women.

Design: Cross-sectional. Data collection included four days of dietary recalls and information on education and current occupation for participants and their spouses. Setting: Philadelphia, PA, USA.

Subjects: Chinese immigrant women ( $n$ 423) recruited from October 2005 to April 2008. Results: In multivariate models, both higher education level and occupation category were significantly associated with higher energy density and intake of energy and sugar. Education was additionally associated with intake of sugar-sweetened beverages $(P=0 \cdot 01)$ and lower dietary moderation $(P=0 \cdot 01)$. With joint categorization based on both education and occupation, we observed significant trends indicating higher energy density $(P=0 \cdot 004)$ and higher intake of energy $(P=0 \cdot 001)$ and sugar $(P=0 \cdot 04)$, but less dietary moderation $(P=0 \cdot 02)$ with higher SEP.

Conclusions: In this sample of US Chinese immigrants, higher SEP as indicated by education level and occupation category was associated with differences in dietary intake and with less dietary moderation. While higher SEP is typically linked to healthier diet in higher-income nations, in these immigrants the association of SEP with diet follows the pattern of their country of origin - a lower-income country undergoing the nutrition transition.
\end{abstract}

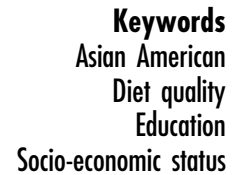

Keywords

Diet quality

Socio-economic status
Lower socio-economic position (SEP), quantified using such indicators as level of education, occupational status and income, is associated with poorer diet and health in higher-income countries, including the USA ${ }^{(1-8)}$. However, these associations may not be valid across all subgroups. Despite their lower SEP, for example, low-acculturation Asian immigrant samples appear to have better diet and health than their more acculturated, higher-SEP peers ${ }^{(9)}$ and the mainstream white population ${ }^{(10,11)}$.

Asian immigrants' transition to increased risk for overweight and chronic disease following migration to the USA $^{(12-21)}$ might be attributed in part to dietary acculturation, or the adoption of the dietary practices of the host population $^{(22)}$. Few studies, however, have examined the association of SEP with dietary intake in US immigrants. The association of SEP with dietary intake among immigrants may parallel the nutrition transition observed in developing countries, in which economic development and higher SEP are associated with less healthy lifestyle and increased risk for chronic disease ${ }^{(8,23)}$. The objective of the present analysis was to describe associations of diet and diet quality with level of education and occupational category as indicators of SEP in a sample of Chinese immigrant women.

\section{Methods}

\section{Study sample}

Between 1 October 2005 and 30 April 2008, we recruited 436 healthy, premenopausal women from community organizations and contacts into a study of diet and mammographic breast density. Eligibility criteria included Chinese heritage, migration from Asia $\leq 20$ years ago and being of mammography screening age. Exclusion criteria were: postmenopausal status (no menstruation in the past year); history of breast augmentation/reduction, prophylactic mastectomy or any cancer except non-melanoma skin cancer; current pregnancy; current breast-feeding or breast-feeding within last 9 months; or symptoms of new breast problem, such as palpable lump, skin changes or nipple discharge. Participants received \$US 20 as reimbursement for their time. The study was approved by the Fox Chase Cancer Center Institutional Review Board. 


\section{Data collection}

Interviewers conducted detailed health interviews that elicited information on various health behaviours, health and reproductive history, and sociodemographic characteristics including level of education, current and usual occupation of the participant and of her spouse, if applicable, and level of acculturation.

Participants were asked about the highest level of education they completed, and responses were collapsed into three categories: (i) 0-8 years; (ii) 9-12 years, with or without completion of high school or vocational/technical school; and (iii) at least some college, university or graduate school. Each participant was also asked to select a category for her own and for her husband's current occupation from among the following: not employed; farmer/farm worker; machine/vehicle operator; crafts worker; service worker; clerical worker; sales worker; manager/administrator; or professional/technical. These were collapsed into three categories: (i) not employed, farmer/farm worker, machine or vehicle operator, crafts worker or service worker; (ii) clerical or sales worker; and (iii) manager/administrator or professional/technical, roughly corresponding to categories used in other research $^{(24,25)}$. In analyses based on husband's occupation, the participant's own occupation was used $(n 44)$ if she was unmarried or her husband was not employed. Results were similar but more pronounced when analyses were based on the participant's husband's rather than her own occupation; thus, analyses on occupation category were based primarily on husband's occupation. For $2 \%(n 8)$ of the sample, no occupation was specified for either the participant or her spouse because both the participant and her spouse were unemployed or because the participant was unemployed and unmarried.

Acculturation was measured using an abridged version of the General Ethnicity Questionnaire - American version (GEQA) ${ }^{(26)}$. The original, thirty-seven-item GEQA scale, developed for immigrant and American-born Chinese college students, was found to have good validity and reliability in Chinese immigrants in previous studies ${ }^{(26,27)}$. For the current study we dropped items that showed little variability in response during pilot testing among a sample of middle-aged Chinese women, most of whom migrated to the USA in adulthood (e.g. 'I was raised in a way that was American', 'How much do you speak English at school?'). The remaining eleven items dealt with exposure to or familiarity with American people, culture and activities (e.g. 'Now, I am exposed to American culture', 'I go to places where people are American', 'I celebrate American holidays') and showed high internal reliability $(\alpha=0 \cdot 91)$.

Trained interviewers followed a standardized protocol for conducting two $48 \mathrm{~h}$ dietary recall interviews about two weeks apart for each participant, with the mean over the four days used in analysis, and for entering responses into the Nutrition Data System for Research (NDS-R;
Nutrition Coordinating Center, University of Minnesota, Minneapolis, MN, USA). Foods not included in the NDS-R database were added by creating recipes for new mixed dishes, or by the Nutrition Coordinating Center, which bases nutrient values on information from food manufacturers, foreign food composition tables, the scientific literature and other available databases. In addition to providing estimates of nutrient intake, the NDS-R assigns each food item to one of 166 possible food subgroups and estimates serving counts for each food subgroup. Food items are counted at the whole food level when appropriate (e.g. bread, apple pie, French fries) or at the component/ingredient level (e.g. lasagne, soup, fruit salad, sandwiches) to capture intake of ingredients. Food subgroup definitions and serving sizes were based primarily on recommendations from the 2005 Dietary Guidelines for Americans ${ }^{(28)}$ and the Food Guide Pyramid $^{(29)}$. Food and Drug Administration serving sizes ${ }^{(30)}$ were used for foods not included among current recommendations, such as cookies and fruit drinks.

\section{Statistical analyses}

Of 436 women enrolled in the study, three women subsequently did not complete baseline questionnaires, and ten were excluded for not having completed dietary interviews ( $n 8)$ or questions on occupation $(n 1)$ or country of birth, an adjustment variable in multivariate regression analyses ( $n$ 1), leaving a sample of 423 women. We observed no statistically significant differences in age, level of education, length of US residence or GEQA score between the sample of 423 women and the ten women with information on these factors but excluded from analysis.

We used the Diet Quality Index-International (DQI-I) ${ }^{(31)}$ to examine four components of diet quality: (i) variety within protein sources and across food groups; (ii) adequacy of intake of vegetables, fruits, grains, fibre, protein, $\mathrm{Fe}, \mathrm{Ca}$ and vitamin $\mathrm{C}$; (iii) moderation of intake of total fat, saturated fat, cholesterol, $\mathrm{Na}$ and empty-calorie foods; and (iv) overall balance with respect to macronutrients and fatty acid composition $^{(31)}$. Details on the components of the DQII are given in the Appendix. Other dietary outcome variables of interest were selected for their direct relevance to diet quality and its components. These included energy density, percentage of energy from fat, carbohydrates and protein, and intakes of total energy, cholesterol, dietary fibre, Na, sugar and sugar-sweetened beverages.

The primary predictors of interest were level of education (three categories) and occupation category (three categories). From these variables, we also created three categories jointly classifying women according to both education and occupation: (i) least educated women in the lowest occupational category; (ii) most educated women in the highest occupational category; and (iii) an intermediate category including all other women. We used linear regression analyses to examine associations of education and occupation as predictors of dietary intake. 
The balance component of the DQI-I could not be treated as a continuous outcome variable. Therefore, to use a consistent approach across all DQI-I components, we created categories of approximate tertiles and then conducted logistic regression analyses for polychotomous outcomes using proportional odds models. Estimates from these models can be interpreted as the log odds of falling into a higher $v$. lower category ${ }^{(32)}$. The score test ${ }^{(32)}$ was used to test the assumption of proportional odds, i.e. that the cumulative logits are equal. Variables for which the assumption of proportional odds was violated (dietary adequacy, DQI-I score) were dichotomized at the median and analysed in logistic regression for binary outcomes. Sugar-sweetened beverages were consumed by less than half of the study sample and so were also analysed as a dichotomous outcome variable (any $v$. no consumption) in logistic regression analyses for binary outcomes.

Models for energy intake, DQI-I score and DQI-I components adjusted for age (continuous years), country of birth (China or elsewhere), marital status (married or not) and GEQA score (continuous). All other models additionally adjusted for energy intake (continuous kcal). Models were first run for education and occupation separately, then for joint categories of education and occupation. Tests for trend were conducted using a variable representing ordinal values for education, occupation or their jointly classified category. All statistical analyses were conducted using the SAS statistical software package version $9 \cdot 1 \cdot 3$ (SAS Institute, Inc., Cary, NC, USA).

\section{Results}

Among the 423 women in the sample, mean (SD) age was $43.9(4.5)$ years, with a range of $35-56$ years (Table 1$)$. The women had lived in the USA for a mean (SD) of $7 \cdot 6(4 \cdot 8)$ years and migrated to the USA at a mean (SD) age of $36 \cdot 4$ (6.5) years. Almost all (97\%) were born in China, and most (70\%) spoke no English at home. Mean (sD) GEQA score was $2 \cdot 1(0 \cdot 7)$, out of a possible range of 1 (least acculturated) to 5 (most acculturated). Half of the women (49\%) reported up to 8 years of education, while $35 \%$ reported at least 9 years of education up to technical or vocational school, and $17 \%$ had at least some college education. Most women (80\%) were classed in the farm-, machine-, craftsor service worker category, $8 \%$ in the clerical or sales worker category, and $12 \%$ in the managers/administrators or professional/technical workers category. Women with a higher level of education or in a higher occupation category had higher mean GEQA score, were more likely to speak English at home and were less likely to be married. Education and occupation categories were also strongly interrelated, with $63 \%$ of women with at least some college education holding an administrator/professional position and $86 \%$ of women in administrator/professional positions having at least some college education.
In linear regression models (Table 2), both higher education level and higher occupation category were associated with higher energy density and higher intakes of energy and sugar. More education was also significantly associated with a higher percentage of energy from fat and, in logistic regression analyses, with a greater likelihood of consuming sugar-sweetened beverages ( $\mathrm{OR}=3.9(95 \% \mathrm{CI}$ $1 \cdot 5,10 \cdot 3)$ for highest $v$. lowest education category, trend $P=0 \cdot 01)$. In logistic regression analyses with diet quality as the outcome variable (Table 3), higher education level was additionally associated with lower dietary moderation. We observed no associations for either education or occupation category with percentage of energy from saturated fat, carbohydrates and protein, with intakes of cholesterol, dietary fibre and $\mathrm{Na}$ (not shown), or with other measures of diet quality.

When women were jointly classified according to both education and occupation categories (Table 4), those in the highest education/occupation category consumed daily an average of $825.5 \mathrm{~kJ}(197 \cdot 3 \mathrm{kcal})$ more energy and $12 \cdot 2 \mathrm{~g}$ more sugar than women in the lowest education/ occupation category. They also had significantly higher dietary energy density. A trend towards lower dietary moderation $(P=0 \cdot 02)$ was also evident, although dietary moderation did not decrease monotonically with SEP category.

\section{Discussion}

The most notable finding in the present sample of Chinese immigrant women was that SEP, as indicated by either education or occupation, was associated with lower dietary moderation. It was also associated with having higher energy density and percentage of energy from fat, higher intakes of energy and sugar, and greater likelihood of consumption of sugar-sweetened beverages.

The finding that higher education was associated with less dietary moderation confirms an association we observed previously in a separate sample of Chinese immigrant women ${ }^{(9)}$. The dietary moderation component of the DQI-I score is of particular interest because it evaluates dietary factors that are related to chronic diseases and that may require restriction ${ }^{(31)}$. Better educated women may have greater access, knowledge, opportunity and/or resources to obtain more foods, leading to less dietary moderation, although this was not reflected in higher dietary variety or adequacy scores in the current sample as it was in the previous sample ${ }^{(9)}$. In fact, in additional analyses in the current sample, we observed an inverse association between education and dietary adequacy when energy was included as a covariate in the logistic regression model (results not shown), contradicting our previous finding that education was associated with higher adequacy ${ }^{(9)}$. This suggests that the more educated women in the current sample did not have less adequate 
Table 1 Sociodemographic variables by education and occupation category in a sample of US Chinese immigrant women ( $n$ 423), Philadelphia, PA, October 2005 to April 2008

\begin{tabular}{|c|c|c|c|c|c|c|c|c|c|c|c|c|c|c|}
\hline & & & \multicolumn{6}{|c|}{ Education category* } & \multicolumn{6}{|c|}{ Occupation category $\dagger$} \\
\hline & \multicolumn{2}{|c|}{ All women ( $n$ 423) } & \multicolumn{2}{|c|}{$1(n 206)$} & \multicolumn{2}{|c|}{$2(n 147)$} & \multicolumn{2}{|c|}{$3(n 70)$} & \multicolumn{2}{|c|}{1 (n 338) } & \multicolumn{2}{|c|}{$2(n 34)$} & \multicolumn{2}{|c|}{$3(n 51)$} \\
\hline & Mean & SD & Mean & SD & Mean & SD & Mean & SD & Mean & SD & Mean & SD & Mean & SD \\
\hline Age (years) & 43.9 & $4 \cdot 5$ & $44 \cdot 1$ & $4 \cdot 7$ & $43 \cdot 8$ & $4 \cdot 3$ & $43 \cdot 6$ & $4 \cdot 4$ & $43 \cdot 8$ & $4 \cdot 5$ & $44 \cdot 9$ & $4 \cdot 5$ & $44 \cdot 1$ & $4 \cdot 6$ \\
\hline Born in China (\%) & \multicolumn{2}{|c|}{97} & \multicolumn{2}{|c|}{98} & \multicolumn{2}{|c|}{96} & \multicolumn{2}{|c|}{97} & \multicolumn{2}{|c|}{97} & \multicolumn{2}{|c|}{94} & \multicolumn{2}{|c|}{100} \\
\hline $\begin{array}{l}\text { Level of education (years; \%) } \\
0-8\end{array}$ & \multirow{2}{*}{\multicolumn{2}{|c|}{49}} & & & & & & & & & & & & \\
\hline $\begin{array}{l}0-8 \\
9-12\end{array}$ & & & & & & & & & \multicolumn{2}{|c|}{57} & & & & 4 \\
\hline At least some college & \multicolumn{2}{|c|}{$17 \ddagger$} & & & & & & & \multicolumn{2}{|c|}{$6 \ddagger$} & & & \multicolumn{2}{|c|}{86} \\
\hline \multicolumn{15}{|l|}{ Occupational category (\%) } \\
\hline $\begin{array}{l}\text { Machine operator, farm, craft or service worker, } \\
\text { or not employed }\end{array}$ & \multicolumn{2}{|c|}{80} & \multicolumn{2}{|c|}{93} & \multicolumn{2}{|c|}{86} & & & & & & & & \\
\hline Clerical or sales worker & & & & & & & & & & & & & & \\
\hline Manager, administrator or professional & & & & & & & & & & & & & & \\
\hline Not married (\%) & & & & & & & & & & & & 3 & & \\
\hline Age at migration (years) & $36 \cdot 4$ & $6 \cdot 5$ & $36 \cdot 6$ & $6 \cdot 3$ & $36 \cdot 5$ & $6 \cdot 6$ & $35 \cdot 6$ & $6 \cdot 8$ & $36 \cdot 3$ & $6 \cdot 5$ & $37 \cdot 1$ & $7 \cdot 0$ & $36 \cdot 3$ & $6 \cdot 4$ \\
\hline Length of US residence (years) & $7 \cdot 5$ & $4 \cdot 8$ & $7 \cdot 5$ & $4 \cdot 6$ & $7 \cdot 3$ & $4 \cdot 7$ & $8 \cdot 0$ & $5 \cdot 4$ & $7 \cdot 5$ & $4 \cdot 7$ & $7 \cdot 8$ & $5 \cdot 1$ & $7 \cdot 8$ & $5 \cdot 2$ \\
\hline Acculturation score & $2 \cdot 1$ & $0 \cdot 7$ & $1 \cdot 9$ & $0 \cdot 6$ & $2 \cdot 1$ & $0 \cdot 7$ & $2 \cdot 9$ & $0 \cdot 6$ & $2 \cdot 0$ & $0 \cdot 7$ & $2 \cdot 4$ & $0 \cdot 6$ & $2 \cdot 9$ & $0 \cdot 6$ \\
\hline Speak no English at home (\%) & & & & & & & & & & & & & & \\
\hline Intake per day & & & & & & & & & & & & & & \\
\hline Energy $(\mathrm{kJ})$ & 5682 & 1519 & 5473 & 1527 & 5820 & 1435 & 6004 & 1598 & 5573 & 1481 & 6017 & 1481 & 6176 & 1699 \\
\hline Energy (kcal) & 1358 & 363 & 1308 & 365 & 1391 & 343 & 1435 & 382 & 1332 & 354 & 1438 & 354 & 1476 & 406 \\
\hline Energy density $(\mathrm{kJ} / \mathrm{g})$ & $3 \cdot 35$ & $1 \cdot 00$ & $3 \cdot 14$ & $1 \cdot 05$ & $3 \cdot 35$ & 0.88 & $4 \cdot 06$ & 0.96 & $3 \cdot 22$ & 0.96 & $3 \cdot 47$ & $0 \cdot 84$ & $4 \cdot 18$ & 1.00 \\
\hline Energy density $(\mathrm{kcal} / \mathrm{g})$ & $0 \cdot 80$ & 0.24 & 0.75 & 0.25 & $0 \cdot 80$ & $0 \cdot 21$ & 0.97 & 0.23 & $0 \cdot 77$ & $0 \cdot 23$ & 0.83 & $0 \cdot 20$ & $1 \cdot 00$ & 0.24 \\
\hline Total fat (\% of energy) & $24 \cdot 5$ & $6 \cdot 1$ & $23 \cdot 5$ & $5 \cdot 9$ & $24 \cdot 3$ & $5 \cdot 9$ & $27 \cdot 7$ & $6 \cdot 1$ & $23 \cdot 9$ & $6 \cdot 0$ & $26 \cdot 2$ & $5 \cdot 9$ & $27 \cdot 1$ & $6 \cdot 2$ \\
\hline Total sugar (g) & $40 \cdot 0$ & $22 \cdot 6$ & $36 \cdot 2$ & $20 \cdot 7$ & $38 \cdot 0$ & $19 \cdot 9$ & $55 \cdot 2$ & $26 \cdot 9$ & $37 \cdot 2$ & $20 \cdot 6$ & $40 \cdot 8$ & $20 \cdot 9$ & $58 \cdot 0$ & $27 \cdot 9$ \\
\hline$\%$ Consuming sugar-sweetened beverages & & & & & & & & & & & & & & \\
\hline Variety & $15 \cdot 6$ & $3 \cdot 4$ & & & & & & & & & & & & \\
\hline Adequacy & $30 \cdot 4$ & $4 \cdot 6$ & $30 \cdot 3$ & $4 \cdot 5$ & $30 \cdot 6$ & $4 \cdot 6$ & $30 \cdot 3$ & $4 \cdot 9$ & $30 \cdot 3$ & $4 \cdot 5$ & $30 \cdot 7$ & $4 \cdot 8$ & $30 \cdot 7$ & $5 \cdot 1$ \\
\hline Moderation & $22 \cdot 4$ & $5 \cdot 2$ & $23 \cdot 4$ & $5 \cdot 0$ & $21 \cdot 6$ & $5 \cdot 3$ & $21 \cdot 3$ & $5 \cdot 3$ & $22 \cdot 7$ & $5 \cdot 2$ & $21 \cdot 3$ & $5 \cdot 1$ & $21 \cdot 6$ & $5 \cdot 3$ \\
\hline Balance & $1 \cdot 87$ & $2 \cdot 00$ & $1 \cdot 80$ & $1 \cdot 90$ & $2 \cdot 03$ & $2 \cdot 17$ & $1 \cdot 77$ & 1.91 & $1 \cdot 85$ & $2 \cdot 00$ & $1 \cdot 65$ & $1 \cdot 67$ & $2 \cdot 20$ & $2 \cdot 20$ \\
\hline DQI-I score & $70 \cdot 4$ & 8.5 & $70 \cdot 9$ & $7 \cdot 9$ & $69 \cdot 8$ & $8 \cdot 7$ & $69 \cdot 7$ & $9 \cdot 5$ & $70 \cdot 3$ & $8 \cdot 3$ & $69 \cdot 8$ & $7 \cdot 7$ & $70 \cdot 9$ & $10 \cdot 0$ \\
\hline
\end{tabular}

${ }^{*}$ Education category: $1=0-8$ years of school; $2=9-12$ years; $3=$ at least some college

†Occupation category: 1 = machine operator, farm, craft or service worker, or not employed; 2 = clerical or sales worker; $3=$ manager, administrator or professional.

¥Proportions do not add to $100 \%$ due to rounding. 
Table 2 Adjusted $\beta$ estimates ${ }^{\star}$ and $P$ values for trend for education and occupation categories in multivariate linear regression models; sample of US Chinese immigrant women ( $n$ 423), Philadelphia, PA, October 2005 to April 2008

\begin{tabular}{|c|c|c|c|c|c|c|c|c|c|c|c|c|}
\hline & \multicolumn{6}{|c|}{ Education category $\dagger$} & \multicolumn{6}{|c|}{ Occupation categorył } \\
\hline & \multirow[b]{2}{*}{$1(n 206)$} & \multicolumn{2}{|c|}{$2(n 147)$} & \multicolumn{2}{|c|}{$3(n 70)$} & \multirow[b]{2}{*}{$P$ for trend $\S$} & \multirow[b]{2}{*}{$1(n 338)$} & \multicolumn{2}{|c|}{$2(n 34)$} & \multicolumn{2}{|c|}{$3(n 51)$} & \multirow[b]{2}{*}{$P$ for trend } \\
\hline & & $\beta$ & $P$ & $\beta$ & $P$ & & & $\beta$ & $P$ & $\beta$ & $P$ & \\
\hline Energy (kcal) & Ref. & $85 \cdot 8$ & 0.03 & $137 \cdot 0$ & 0.01 & 0.002 & Ref. & $107 \cdot 5$ & $0 \cdot 11$ & $153 \cdot 2$ & 0.01 & 0.002 \\
\hline Energy density $(\mathrm{kcal} / \mathrm{g})$ & Ref. & 0.01 & 0.54 & $0 \cdot 12$ & 0.0002 & 0.002 & Ref. & -0.01 & 0.88 & $0 \cdot 12$ & 0.0004 & 0.001 \\
\hline Total fat ( $\%$ of energy) & Ref. & $0 \cdot 3$ & 0.64 & $2 \cdot 3$ & 0.01 & 0.03 & Ref. & $1 \cdot 2$ & 0.27 & $1 \cdot 3$ & 0.20 & $0 \cdot 14$ \\
\hline Total sugar $(\mathrm{g})$ & Ref. & $-1 \cdot 6$ & 0.44 & $9 \cdot 4$ & 0.002 & 0.04 & Ref. & $-1 \cdot 4$ & 0.69 & $11 \cdot 8$ & 0.0002 & 0.001 \\
\hline
\end{tabular}

Ref., referent category.

${ }^{*}$ Adjusted for age, marital status, birthplace and score on General Ethnicity Questionnaire - American version. All models except for energy intake were also adjusted for energy intake.

†Education category: $1=0-8$ years of school; $2=9-12$ years; $3=$ at least some college.

‡Occupation category: $1=$ machine operator, farm, craft or service worker, or not employed; $2=$ clerical or sales worker; $3=$ manager, administrator or professional.

$\S P$ values for trend estimated by including education or occupation category as an ordinal variable in the linear regression model.

Table 3 Adjusted odds ratio* and corresponding $95 \%$ confidence interval for being in a higher category for Diet Quality Index-International (DQI-I) scores, estimated from logistic regression; sample of US Chinese immigrant women ( $n$ 423), Philadelphia, PA, October 2005 to April 2008

\begin{tabular}{|c|c|c|c|c|c|c|c|c|c|c|c|c|}
\hline & \multicolumn{6}{|c|}{ Education category† } & \multicolumn{6}{|c|}{ Occupation category } \\
\hline & \multirow[b]{2}{*}{$1(n 206)$} & \multicolumn{2}{|c|}{$2(n 147)$} & \multicolumn{2}{|c|}{$3(n 70)$} & \multirow[b]{2}{*}{$P$ for trend§ } & \multirow[b]{2}{*}{$1(n 338)$} & \multicolumn{2}{|c|}{$2(n 34)$} & \multicolumn{2}{|c|}{$3(n 51)$} & \multirow[b]{2}{*}{$P$ for trend $\S$} \\
\hline & & OR & $95 \% \mathrm{Cl}$ & OR & $95 \% \mathrm{Cl}$ & & & OR & $95 \% \mathrm{Cl}$ & OR & $95 \% \mathrm{Cl}$ & \\
\hline Variety\| & $1 \cdot 0$ & $1 \cdot 0$ & $0.6,1.5$ & $1 \cdot 3$ & $0 \cdot 7,2 \cdot 3$ & 0.44 & $1 \cdot 0$ & $1 \cdot 4$ & $0 \cdot 7,2 \cdot 8$ & $1 \cdot 4$ & $0 \cdot 8,2 \cdot 5$ & 0.47 \\
\hline Adequacy & $1 \cdot 0$ & $1 \cdot 3$ & $0 \cdot 9,2 \cdot 1$ & 0.8 & $0.5,1.6$ & 0.87 & $1 \cdot 0$ & $1 \cdot 2$ & $0 \cdot 6,2 \cdot 4$ & $1 \cdot 1$ & $0 \cdot 6,2 \cdot 1$ & 0.74 \\
\hline Moderation $\|$ & $1 \cdot 0$ & 0.6 & $0 \cdot 4,0 \cdot 8$ & 0.6 & $0 \cdot 3,1 \cdot 1$ & 0.01 & $1 \cdot 0$ & 0.6 & $0 \cdot 3,1 \cdot 1$ & 0.8 & $0.4,1.5$ & 0.39 \\
\hline Balancell & $1 \cdot 0$ & $1 \cdot 2$ & $0 \cdot 8,1 \cdot 8$ & $1 \cdot 1$ & $0 \cdot 6,2 \cdot 0$ & 0.49 & $1 \cdot 0$ & $1 \cdot 0$ & $0.5,1.9$ & $1 \cdot 5$ & $0 \cdot 8,2 \cdot 8$ & $0 \cdot 81$ \\
\hline DQI-I score & $1 \cdot 0$ & 0.8 & $0.5,1 \cdot 3$ & 0.8 & $0.4,1 \cdot 4$ & 0.31 & $1 \cdot 0$ & $1 \cdot 1$ & $0 \cdot 5,2 \cdot 2$ & $1 \cdot 2$ & $0 \cdot 6,2 \cdot 3$ & $0 \cdot 40$ \\
\hline
\end{tabular}

*Adjusted for age, marital status, birthplace and score on General Ethnicity Questionnaire - American version.

+Education category: $1=0-8$ years of school; $2=9-12$ years; $3=$ at least some college.

fOccupation category: 1 = machine operator, farm, craft or service worker, or not employed; $2=$ clerical or sales worker; $3=$ manager, administrator or professional.

$\$ P$ values for trend estimated by including education or occupation category as an ordinal variable in the logistic regression model.

\|Modelled in logistic regression for polychotomous outcome, with outcome categorized into tertiles.

- Modelled in logistic regression for binary outcome (above $v$. below median).

Table 4 Adjusted $\beta$ estimates* and $P$ values for trend for jointly categorized education and occupation in multivariate linear or logistic regression models; sample of US Chinese immigrant women ( $n$ 423), Philadelphia, PA, October 2005 to April 2008

\begin{tabular}{|c|c|c|c|c|c|c|}
\hline & \multicolumn{6}{|c|}{ Joint categories of education and occupationt } \\
\hline & \multirow[b]{2}{*}{$1(n$ 192) } & \multicolumn{2}{|c|}{$2(n 187)$} & \multicolumn{2}{|c|}{$3(n 44)$} & \multirow[b]{2}{*}{$P$ for trenc } \\
\hline & & $\beta \ddagger$ & $P$ value & $\beta \ddagger$ & $P$ value & \\
\hline Energy (kcal) & Ref. & $92 \cdot 7$ & 0.01 & $197 \cdot 3$ & 0.004 & 0.001 \\
\hline Energy density (kcal/g) & Ref. & 0.01 & 0.56 & 0.15 & 0.0001 & 0.004 \\
\hline Total fat ( $\%$ of energy) & Ref. & 0.5 & 0.42 & $1 \cdot 4$ & 0.21 & 0.20 \\
\hline \multirow[t]{2}{*}{ Total sugar $(\mathrm{g})$} & Ref. & -0.9 & 0.65 & $12 \cdot 2$ & 0.0008 & 0.04 \\
\hline & & OR & $95 \% \mathrm{Cl}$ & OR & $95 \% \mathrm{Cl}$ & \\
\hline Sweetened beverages $\S$ & $1 \cdot 0$ & $1 \cdot 6$ & $0.8,3 \cdot 5$ & $2 \cdot 7$ & $0 \cdot 9,8 \cdot 1$ & 0.07 \\
\hline Variety\| & $1 \cdot 0$ & $1 \cdot 1$ & $0 \cdot 8,1 \cdot 6$ & $1 \cdot 3$ & $0 \cdot 7,2 \cdot 6$ & $0 \cdot 39$ \\
\hline Adequacy & $1 \cdot 0$ & 0.9 & $0 \cdot 5,1 \cdot 4$ & 0.6 & $0 \cdot 2,1 \cdot 4$ & 0.27 \\
\hline Moderation $\mid$ & $1 \cdot 0$ & $0 \cdot 6$ & $0 \cdot 4,0.8$ & $0 \cdot 8$ & $0 \cdot 3,1 \cdot 4$ & 0.02 \\
\hline Balancell & $1 \cdot 0$ & $1 \cdot 1$ & $0 \cdot 8,1 \cdot 7$ & $1 \cdot 5$ & $0 \cdot 7,2 \cdot 9$ & 0.28 \\
\hline DQI-I score & $1 \cdot 0$ & $0 \cdot 7$ & $0.5,1 \cdot 1$ & $0 \cdot 7$ & $0.3,1.5$ & $0 \cdot 15$ \\
\hline
\end{tabular}

Ref., referent category; DQI-I, Diet Quality Index-International.

*Adjusted for age, marital status, birthplace and score on General Ethnicity Questionnaire - American version. Models for energy density, total fat and total sugar also adjusted for energy intake.

tJoint education/occupation category: 1 = 0-8 years of school and machine operator, farm, craft or service worker, or not employed; $3=$ at least some college and manager, administrator or professional; $2=$ all others.

$\ddagger$ Modelled in linear regression.

$\S$ Modelled in logistic regression for binary outcome (consumer $v$. non-consumer).

$\|$ Modelled in logistic regression for polychotomous outcome.

- Modelled in logistic regression for binary outcome (above $v$. below median). 
diets per se because they had higher energy intake overall. However, their diets were less adequate (i.e. less nutrientdense) for a given level of energy intake, as indicated by the inverse association between education and dietary adequacy when energy intake was controlled for.

Associations with dietary factors were more apparent when education and occupation were considered separately rather than simultaneously in models. For example, energy density was significantly associated with both education and occupation in models including each SEP variable individually, but it was no longer significantly associated with either in a model including both at the same time. This is likely due to the substantial overlap between education and occupation categories, leaving less power to detect trends within strata when participants were simultaneously classified according to both education and occupation. Overall, our findings suggest that women of higher SEP consumed diets that were higher in energy, fat and sugar, with stronger associations observed for education as an indicator of SEP.

Higher SEP has been linked to better diet and health, and lower SEP to poorer diet and health, in higherincome nations $^{(1-8)}$. In low-income, developing countries, however, the opposite is true. Using income elasticity to quantify effects of income on food consumption in China, for example, Du et al. $^{(33)}$ found that increased income was linked to a greater likelihood of consuming poultry and beef, and to a high-fat diet overall. In another analysis, Kim et $a l^{(23)}$ found that markers of a healthy lifestyle (based on diet quality, physical activity, smoking, alcohol use) increased with income and education in the USA but decreased with these SEP indicators in China. Recent reviews of the literature on SEP and obesity in countries at different stages of economic development demonstrate a similar phenomenon: risk of obesity tends to decrease with SEP in higher-income countries but to increase with SEP in lower-income countries ${ }^{(8,34)}$; associations are mixed in middle-income countries, indicating a shift in the burden of obesity from high- to low-SEP individuals.

Our findings suggest that among immigrants to higherincome countries, the association of SEP with diet follows the pattern of their country of origin. Consistent with this, a study conducted in the Netherlands observed a different association of SEP with diet between immigrant and nonimmigrant residents; education was positively associated with diet quality among ethnic Dutch but not consistently among Surinamese immigrants ${ }^{(35)}$. Another study, while not conducted among immigrants, also demonstrates that the association of SEP with diet and health is not homogeneous across all population subgroups within a country. Among adults in the lowest quintile of income in seven states in Mexico, SEP, quantified using six different indicators, was positively associated with obesity, although the association between SEP and obesity is inverse in Mexico overall; the association was mediated in part by increased consumption of alcohol and soda ${ }^{(36)}$.
In higher-income countries, better diet quality with higher SEP may be due to better health knowledge and to greater financial capacity to purchase more nutritious, and costlier, foods ${ }^{(8,23)}$. McLaren ${ }^{(8)}$, citing the sociologist Pierre Bourdieu, also suggests that SEP, or 'class', can be viewed as a 'constellation of attributes' including thinness and a healthy lifestyle, and that valuing such attributes may be internalized to distinguish among classes. In lower-income countries, however, the economic/material rather than social dimension of SEP or class is more important $^{(8)}$, and SEP reflects greater purchasing power, access to a larger variety of foods and pursuit of new, not necessarily healthful dietary norms, desirable because of current or prior popularity of these products among individuals of higher $\operatorname{SEP}^{(8,23,36)}$. The implication for US immigrants is that an improved SEP, reflecting greater economic resources, may not have beneficial effects on diet and health as it does in the general US population. A reversal of this association - that is, for SEP to be associated with improved diet and health - may require acculturation in the form of internalization of the 'constellation of attributes', including social and health-related attributes, that define higher SEP in the USA. Additional analyses stratified on level of acculturation in the current sample of women did not reveal clear evidence that higher SEP was differently associated with better diet among women who were more acculturated (not shown). However, level of acculturation in the sample was low overall, and a greater range in level of acculturation may be required to detect such a difference in effect. Such acculturation may be difficult to achieve through health education. Providing immigrants with the opportunity and resources to achieve full social and economic integration would allow them to internalize class-related norms and to enjoy the health advantages that accompany higher SEP in the USA.

Some limitations of our study are worth mentioning. First, this was a convenience sample of women of generally low acculturation and low SEP, raising the possibility of limited variability and generalizability. Nevertheless, the fact that we were able to detect significant differences in dietary intake even within this relatively homogeneous group points to the strength of effect of SEP on dietary behaviours and merits confirmation in other samples. Second, the sample is limited in size, although this allowed for a notable strength of the study - the ability to collect detailed, quantitative dietary data from participants in the form of multiple dietary recall interviews. We used $48 \mathrm{~h}$ recalls, rather than $24 \mathrm{~h}$ recalls, in order to balance the need to capture greater intra-individual variability in dietary intake with the logistical difficulty of trying to reach participants for interviews on multiple days. Additional analyses comparing the distributions of several nutrient variables based on days 2 and 4 of the four dietary recall days (the equivalent of two regular $24 \mathrm{~h}$ recalls) with distributions based on all four days from the two $48 \mathrm{~h}$ recalls showed comparable means, and the expected increase in variance in distributions based on only 
two rather than four days of recalls. Multiple comparisons are a potential limitation in this analysis, although the variables examined were selected a priori based on our research question and the prior literature.

In addition, we measured only education level and occupation as indicators of SEP, and the extent to which these adequately represented SEP in this sample is unclear. Associations with occupation may have been attenuated as a result of the relative homogeneity of our sample with respect to occupation. The appropriateness of using husband's occupation as the basis for categorization is another concern $^{(37)}$, although our preliminary analyses showed stronger results when based on husband's occupation than when based on the woman's own occupation (results not shown). We speculate that, in some cases, the husband's occupation might more closely reflect true SEP or social status than the woman's occupation, which may account for the stronger findings when using husband's occupation. Further, because we did not collect information on income, we were unable to evaluate whether associations of SEP with diet might be due to differences in financial resources and purchasing power. In her review of SEP and obesity, McLaren ${ }^{(8)}$ found that income and material wealth were the SEP indicators most strongly associated with obesity in countries undergoing a nutrition transition. Recent work also suggests that traditional indicators of SEP may not capture all dimensions of SEP in immigrant populations; education, for example, may not translate into the same gains in status and resources as it would in a non-immigrant population ${ }^{(38)}$. Examining a variety of different SEP indicators capturing other dimensions of SEP (e.g. wealth, subjective social status) may provide further insight into mechanisms by which SEP influences dietary behaviours.

Finally, the associations reported here are cross-sectional only. We are aware of no longitudinal data describing social mobility or changes in SEP or in relation to dietary behaviors or health in a Chinese immigrant sample. Whether change in SEP over time influences dietary changes deserves consideration in future work ${ }^{(39)}$.

In summary, we found significant differences in dietary intake and dietary moderation across categories of SEP in this sample of Chinese immigrant women. These findings suggest that dietary differences in immigrants may not, as often supposed, be completely attributable to differences in level of acculturation but may in fact be due partly to differences in SEP. Our findings also demonstrate that higher SEP in immigrants is not associated with better diet; rather, an association of SEP with less dietary moderation follows the pattern of their country of origin, in this case a lower-income country undergoing the nutrition transition. While these findings require confirmation in longitudinal studies, they suggest the importance among US immigrants of establishing and internalizing a change in norms regarding desirability of a healthy diet and lifestyle, regardless of whether the healthy diet is achieved through traditional or American eating habits.

\section{Acknowledgements}

This work was supported by grants R01 CA106606 and P30 CA006927 from the National Institutes of Health. There are no conflicts of interest. M.T. was responsible for initiating the study, analysing the data and drafting the manuscript. C.Y.F. contributed to interpretation of results and suggestions towards subsequent drafts of the manuscript. The authors are indebted to Ms Wanzi Yang, Ms Qi He, Ms Rong Cheng, Ms Bingqin Zheng, Dr Zemin Liu and Ms Yun Song for their crucial work in the collection and management of data for this study. The authors also thank Dr Yu-Wen Ying for her assistance with the General Ethnicity Questionnaire; $\mathrm{Mr}$ Andrew Balshem and the Fox Chase Cancer Center Population Studies Facility for their data management support; and Dr Philip Siu and Dr Thomas Yuen of Chinatown Medical Services for their generous assistance in participant recruitment.

\section{References}

1. House JS, Lantz PM \& Herd P (2005) Continuity and change in the social stratification of aging and health over the life course: evidence from a nationally representative longitudinal study from 1986 to 2001/2002 (Americans' Changing Lives Study). J Gerontol B Psychol Sci Soc Sci 60, 15-26.

2. Galobardes B, Morabia A \& Bernstein MS (2001) Diet and socioeconomic position: does the use of different indicators matter? Int J Epidemiol 30, 334-340.

3. Kant AK \& Graubard BI (2007) Secular trends in the association of socio-economic position with self-reported dietary attributes and biomarkers in the US population: National Health and Nutrition Examination Survey (NHANES) 1971-1975 to NHANES 1999-2002. Public Health Nutr 10, 158-167.

4. Irala-Estevez JD, Groth M, Johansson L et al. (2000) A systematic review of socio-economic differences in food habits in Europe: consumption of fruit and vegetables. Eur J Clin Nutr 54, 706-714.

5. Lopez-Azpiazu I, Sanchez-Villegas A, Johansson L et al. (2003) Disparities in food habits in Europe: systematic review of educational and occupational differences in the intake of fat. J Hum Nutr Diet 16, 349-364.

6. Shimakawa T, Sorlie P, Carpenter MA et al. (1994) Dietary intake patterns and sociodemographic factors in the Atherosclerosis Risk in Communities study. Prev Med 23, 769-780

7. Smith GD, Bartley M \& Blane D (1990) The Black report on socioeconomic inequalities in health 10 years on. BMJ 301, 373-377.

8. McLaren L (2007) Socioeconomic status and obesity. Epidemiol Rev 29, 29-48.

9. Liu A, Berhane Z \& Tseng M (2010) Improved dietary variety and adequacy but lower dietary moderation with acculturation in Chinese women in the United States. $J$ Am Diet Assoc 110, 457-462.

10. Diez Roux AV, Detrano R, Jackson S et al. (2005) Acculturation and socioeconomic position as predictors of coronary calcification in a multiethnic sample. Circulation 112, 1557-1565.

11. Lutsey PL, Diez Roux AV, Jacobs DR Jr et al. (2008) Associations of acculturation and socioeconomic status with subclinical cardiovascular disease in the multi-ethnic study of atherosclerosis. Am J Public Health 98, 1963-1970. 
12. Lauderdale DS \& Rathouz PJ (2000) Body mass index in a US national sample of Asian Americans: effects of nativity, years since immigration and socioeconomic status. Int $J$ Obes Relat Metab Disord 24, 1188-1194.

13. Cook LS, Goldoft M, Schwartz SM et al. (1999) Incidence of adenocarcinoma of the prostate in Asian immigrants to the United States and their descendants. J Urol 161, 152-155.

14. Flood DM, Weiss NS, Cook LS et al. (2000) Colorectal cancer incidence in Asian migrants to the United States and their descendants. Cancer Causes Control 11, 403-411.

15. Ueshima H, Okayama A, Saitoh S et al. (2003) Differences in cardiovascular disease risk factors between Japanese in Japan and Japanese-Americans in Hawaii: the INTERLIPID study. J Hum Hypertens 17, 631-639.

16. Stanford JL, Herrinton LJ, Schwartz SM et al. (1995) Breast cancer incidence in Asian migrants to the United States and their descendants. Epidemiology 6, 181-183.

17. Kandula NR, Diez-Roux AV, Chan C et al. (2008) Association of acculturation levels and prevalence of diabetes in the multi-ethnic study of atherosclerosis (MESA). Diabetes Care 31, 1621-1628.

18. Goel MS, McCarthy EP, Phillips RS et al. (2004) Obesity among US immigrant subgroups by duration of residence. JAMA 292, 2860-2867.

19. Huang B, Rodriguez BL, Burchfiel CM et al. (1996) Acculturation and prevalence of diabetes among JapaneseAmerican men in Hawaii. Am J Epidemiol 144, 674-681.

20. Reed D, McGee D, Cohen J et al. (1982) Acculturation and coronary heart disease among Japanese men in Hawaii. Am J Epidemiol 115, 894-905.

21. Marmot MG \& Syme SL (1976) Acculturation and coronary heart disease in Japanese-Americans. Am J Epidemiol 104, 225-247.

22. Satia JA, Patterson RE, Neuhouser ML et al. (2002) Dietary acculturation: applications to nutrition research and dietetics. J Am Diet Assoc 102, 1105-1118.

23. Kim S, Symons M \& Popkin BM (2004) Contrasting socioeconomic profiles related to healthier lifestyles in China and the United States. Am J Epidemiol 159, 184-191.

24. Turrell G, Hewitt B, Patterson C et al. (2003) Measuring socio-economic position in dietary research: is choice of socio-economic indicator important? Public Health Nutr $\mathbf{6}$, 191-200.

25. Lallukka T, Laaksonen M, Rahkonen O et al. (2007) Multiple socio-economic circumstances and healthy food habits. Eur J Clin Nutr 61, 701-710.

26. Tsai JL, Ying Y \& Lee P (2000) The meaning of 'Being Chinese' and 'Being American': variation among Chinese American young adults. J Cross Cult Psychol 31, 302-332.
27. Ying Y (2001) Migration and cultural orientation: an empirical test of the psychoanalytic theory in Chinese Americans. J Appl Psychoanal Stud 3, 409-430.

28. US Department of Health and Human Services, US Department of Agriculture (2005) Dietary Guidelines for Americans, 2005, 6th ed. Washington, DC: US Government Printing Office.

29. US Department of Agriculture (2005) MyPyramid.gov. http://www.mypyramid.gov/index.html (accessed December 2009).

30. Food and Drug Administration (2001) Food and Drugs: Food Labeling. http://ecfr.gpoaccess.gov/cgi/t/text/text-idx?c=ecfr $\&$ sid $=563$ f0b6235 da3f4c7912a64cbceec305\&rgn $=$ div8\&view $=$ text $\&$ node $=21: 2 \cdot 0 \cdot 1 \cdot 1 \cdot 2 \cdot 1 \cdot 1.8 \&$ idno $=21 \quad$ (accessed December 2009).

31. Kim S, Haines PS, Siega-Riz AM et al. (2003) The Diet Quality Index-International (DQI-I) provides an effective tool for cross-national comparison of diet quality as illustrated by China and the United States. J Nutr 133, 3476-3484.

32. Stokes ME, Davis CS \& Koch GG (1995) Categorical Data Analysis Using the SAS System. Cary, NC: SAS Institute Inc.

33. Du S, Mroz TA, Zhai F et al. (2004) Rapid income growth adversely affects diet quality in China - particularly for the poor! Soc Sci Med 59, 1505-1515.

34. Monteiro CA, Moura EC, Conde WL et al. (2004) Socioeconomic status and obesity in adult populations of developing countries: a review. Bull World Health Organ 82, 940-946.

35. Nicolaou M, van Dam RM \& Stronks K (2006) Acculturation and education level in relation to quality of the diet: a study of Surinamese South Asian and Afro-Caribbean residents of the Netherlands. J Hum Nutr Diet 19, 383-393.

36. Fernald LC (2007) Socio-economic status and body mass index in low-income Mexican adults. Soc Sci Med 64 , 2030-2042.

37. Krieger N, Chen JT \& Selby JV (1999) Comparing individual-based and household-based measures of social class to assess class inequalities in women's health: a methodological study of 684 US women. J Epidemiol Community Health 53, 612-623.

38. de Castro AB, Gee GC \& Takeuchi DT (2010) Examining alternative measures of social disadvantage among Asian Americans: the relevance of economic opportunity, subjective social status, and financial strain for health. J Immigr Minor Health 12, 659-671.

39. Powers MG \& Seltzer W (1998) Occupational status and mobility among undocumented immigrants by gender. Int Migr Rev 32, 21-55. 


\section{Appendix}

Components and scoring criteria for the DQI-I, adapted from Kim et al. ${ }^{(31)}$

\begin{tabular}{|c|c|c|}
\hline Component & Maximum score & Scoring criteria \\
\hline \multicolumn{3}{|l|}{ Variety } \\
\hline $\begin{array}{l}\text { Overall food group variety (meat/poultry/fish/eggs; } \\
\text { dairy/beans; grain; fruit; vegetables) }\end{array}$ & 15 & $\begin{aligned} & \text { 15: } \geq 1 \text { serving/d from each food group } \\
& \text { 12: Any } 1 \text { food group missing } \\
& \text { 9: Any } 2 \text { food groups missing } \\
& \text { 6: Any } 3 \text { food groups missing } \\
& \text { 3: } \geq 4 \text { food groups missing } \\
& 0: \text { None from any food groups }\end{aligned}$ \\
\hline $\begin{array}{l}\text { Within-group variety for protein source } \\
\text { (meat, poultry, fish, dairy, beans, eggs) }\end{array}$ & 5 & 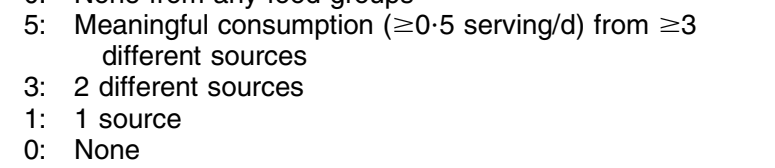 \\
\hline Maximum score & 20 & \\
\hline \multicolumn{3}{|l|}{ Adequacy* } \\
\hline Vegetable group & 5 & $\begin{array}{l}\text { 5: } \geq 3-5 \text { servings } / d \\
0: 0 \text { servings } / d\end{array}$ \\
\hline Fruit group & 5 & $\begin{array}{l}\text { 5: } \geq 2-4 \text { servings } / d \\
0: \quad 0 \text { servings } / d\end{array}$ \\
\hline Grain group & 5 & $\begin{array}{l}5: \quad \geq 6-11 \text { servings } / d \\
0: \quad 0 \text { servings } / d\end{array}$ \\
\hline Fibre & 5 & $\begin{array}{l}5: \quad \geq 20-30 \mathrm{~g} / \mathrm{d} \\
0: \quad 0 \mathrm{~g} / \mathrm{d}\end{array}$ \\
\hline Protein & 5 & $\begin{array}{l}5: \geq 10 \% \text { of energy } \\
0: \quad 0 \% \text { of energy }\end{array}$ \\
\hline $\mathrm{Fe}$ & 5 & $\begin{array}{l}\text { 5: } \geq 100 \% \text { RDA } \\
0: \quad 0 \% \text { RDA }\end{array}$ \\
\hline $\mathrm{Ca}$ & 5 & $\begin{array}{l}\text { 5: } \geq 100 \% \mathrm{Al} \\
0: \quad 0 \% \mathrm{Al}\end{array}$ \\
\hline Vitamin C & 5 & $\begin{array}{l}5: \geq 100 \% \text { RDA } \\
0: \quad 0 \% \text { RDA }\end{array}$ \\
\hline Maximum score & 40 & \\
\hline \multicolumn{3}{|l|}{ Moderation } \\
\hline Total fat & 6 & $\begin{array}{l}\text { 6: } \leq 20 \% \text { of total energy } \\
3: \quad>20-30 \% \text { of total energy } \\
0:>30 \% \text { of total energy }\end{array}$ \\
\hline Saturated fat & 6 & $\begin{array}{l}6: \leq 7 \% \text { of total energy } \\
3:>7-10 \% \text { of total energy } \\
0:>10 \% \text { of total energy }\end{array}$ \\
\hline Cholesterol & 6 & $\begin{array}{l}\text { 6: } \quad \leq 300 \mathrm{mg} / \mathrm{d} \\
\text { 3: }>300-400 \mathrm{mg} / \mathrm{d} \\
0:>400 \mathrm{mg} / \mathrm{d}\end{array}$ \\
\hline $\mathrm{Na}$ & 6 & $\begin{array}{l}6: \quad \leq 2400 \mathrm{mg} / \mathrm{d} \\
3: \quad>2400-3400 \mathrm{mg} / \mathrm{d} \\
0: \quad>3400 \mathrm{mg} / \mathrm{d}\end{array}$ \\
\hline Empty-calorie foodst & 6 & $\begin{array}{l}6: \leq 3 \% \text { of total energy } \\
3:>3-10 \% \text { of total energy } \\
0:>10 \% \text { of total energy }\end{array}$ \\
\hline Maximum score & 30 & \\
\hline \multicolumn{3}{|l|}{ Overall balance } \\
\hline Macronutrient ratio (carbohydrate : protein : fat) & 6 & $\begin{array}{ll}6: & 55-65: 10-15: 15-25 \\
4: & 52-<55 \text { or }>65-68: 9-<10 \text { or }>15-16: 13-<15 \text { or } \\
& >25-27 \\
2: & 50-<52 \text { or }>68-70: 8-<9 \text { or }>16-17: 12-<13 \text { or }>27-30 \\
0: & \text { Otherwise }\end{array}$ \\
\hline Fatty acid ratio & 4 & $\begin{array}{l}\text { 4: } P: S 1-1.5 \text { and } M: S 1-1.5 \\
\text { 2: } P: S 0 \cdot 8-<1 \text { or }>1.5-1.7 \text { and } M: S 0.8-<1 \text { or }>1.5-1 \cdot 7 \\
0: \text { Otherwise }\end{array}$ \\
\hline Maximum score & 10 & \\
\hline
\end{tabular}

DQI-I, Diet Quality Index-International; Al, Adequate Intake; P:S, ratio of polyunsaturated to saturated fatty acid intake; M:S, ratio of monounsaturated to saturated fatty acid intake.

*All sub-scores coded as continuous. Recommended intake of food groups depending on three levels of energy intake ( $\leq 7950 \mathrm{~kJ}$ ( $\leq 1900 \mathrm{kcal}$ ), $>7950-10460 \mathrm{~kJ}$ $(>1900-2500 \mathrm{kcal})$ and $>10460 \mathrm{~kJ}(>2500 \mathrm{kcal}))$. Nutrients evaluated by percentage attainment of dietary recommended intakes.

tDefined as foods for which sum of nutrient densities across fifteen nutrients (protein, vitamin $A$, thiamin, riboflavin, vitamin $B_{6}$, vitamin $B_{12}$, niacin, folate, vitamin $C$, vitamin $\mathrm{E}, \mathrm{Ca}, \mathrm{P}, \mathrm{Fe}, \mathrm{Mg}$ and $\mathrm{Zn}$ ) is $<1$. Nutrient density calculated as (nutrient content/recommended nutrient intake)/(energy content/recommended energy intake). Recommended nutrient intake levels varied by age. Recommended energy intake was based on level of physical activity reported by participant. 